\title{
The effect of CPP-ACP and Nd:YAG laser on the bond strength of softened dentin
}

\section{Maria Beatriz Beber KAMOZAKI ${ }^{(a)}$ Anuradha PRAKKI(b) Letícia Carvalho Coutinho Costa PEROTE(a) \\ Natalia Cortez GUTIERREZ(a) Clovis PAGANI(a)}

(a) Universidade Estadual Paulista - UNESP, Institute of Science and Technology, Department of Restorative Dentistry, São José dos Campos, SP, Brazil.

(b) University of Toronto, Faculty of Dentistry, Department of Clinical Sciences (Restorative), Toronto, ON, Canada.

Declaration of Interests: The authors certify that they have no commercial or associative interest that represents a conflict of interest in connection with the manuscript.

Corresponding Author:

Maria Beatriz Beber Kamozaki

E-mail: bia.kamozaki@gmail.com

DOI: 10.1590/1807-3107BOR-2015.vol29.0068

Submitted: Nov 19, 2014

Accepted for publication: Feb 06, 2015

Last revision: May 05, 2015
Abstract: The purpose of this study was to investigate the effect of CPP-ACP treatment and Nd:YAG laser on microtensile bond strength $(\mu \mathrm{TBS})$ of softened dentin. Sixty samples were obtained from thirty sound third molars. All samples were submitted to dentin softening procedure, by the immersion of the specimens in $30 \mathrm{~mL}$ of Sprite Zero for 30min. Afterwards, the samples were randomly divided according to the CPP-ACP treatment: CG-Control group; MP-treated with CPP-ACP paste (MI Paste); MPP-treated with CPP-ACP+900 ppm NaF paste (MI Paste Plus). Each group was further divided according to bonding procedure: NL-No laser; L-Laser irradiation after adhesive application and before polymerization. The laser parameters used were $1.4 \mathrm{~W}$, $10 \mathrm{~Hz}, 140 \mathrm{~mJ} /$ pulse, with an optic fiber of $320 \mu \mathrm{m}$, generating energy of $174 \mathrm{~J} / \mathrm{cm}^{2}$ per pulse. All samples were restored with Clearfil SE Bond/Filtek Z350 XT. After $24 \mathrm{~h}$, the restored samples were cut into beams $\left( \pm 1 \mathrm{~mm}^{2}\right.$ adhesive interface area) and subjected to a $\mu$ TBS test. Data were analyzed by two-way ANOVA test and Holm-Sidak post-hoc method $(\alpha=0.05)$. The treatment with CPP-ACP pastes did not significantly affect softened dentin $\mu$ TBS $(p=0.070)$. Statistic revealed significant reduction on $\mu$ TBS values for $C G / L$, leading to the rejection of the second null hypothesis $(\mathrm{p}<0.001)$. Both CPP-ACP based pastes did not affect $\mu$ TBS of softened dentin for the adhesive system utilized. The Nd:YAG laser irradiation after application of adhesive system did affect $\mu$ TBS values of softened dentin samples untreated with CPP-ACP based pastes.

Keywords: Caseins; Dentin-Bonding Agents; Lasers, Solid-State.

\section{Introduction}

The prevalence of erosive tooth wear is growing steadily. To properly diagnose and prevent such disorder, it is necessary to understand its pattern. Erosion is characterized by initial surface softening and subsequent bulk material loss trigged by non-bacterial acids. These acids stem from intrinsic or extrinsic sources. ${ }^{1}$ The intrinsic causes are related to the gastric juice entering the mouth by reflux disease, vomiting arising from eating disorders, chronic alcoholism and pregnancy. ${ }^{2}$ The extrinsic causes are due to excessive consumption of acidic beverages such as soft drinks or sport drinks, to some oral hygiene products, occupation and environment. ${ }^{3}$ In certain cases, the restorative treatment is of choice to protect exposed dentin. In other cases, desensitizing products are indicated 
to prevent and treat sensitivity, mostly by providing the remineralization or obliteration of dentin tubules.

The casein phosphopeptides derived from milk proteins have been reported to bind amorphous calcium phosphate forming nanoclusters of casein phosphopeptide amorphous calcium phosphate (CPP-ACP). ${ }^{4}$ The CPP-ACP when placed onto a tooth surface, releases calcium and phosphate ions, therefore maintaining the environment supersaturated. Promising results have been achieved in human and bovine teeth, in which reduced surface demineralization and increased remineralization were reported. ${ }^{5,6}$ The CPP-ACP is available in a commercial topical paste as well as in association of CPP-ACP and fluorine. Some authors have concluded that the fluorine is able to increase the remineralization potential of CPP-ACP. ${ }^{78}$ Few studies that have assessed treatment of sound dentin with CPP-ACP followed by adhesive procedures, noted that the $\mathrm{CPP}-\mathrm{ACP}$ pastes do not decrease the bond strength.,10,11

Alternatives aiming at improving the quality of the adhesive interface have been considered by some authors. Of these, the use of Nd:YAG (neodymium-doped: yttrium aluminium garnet) laser is gaining popularity. ${ }^{12,13}$ This type of laser has been shown to be effective on several applications as preventing erosion, ${ }^{14}$ hy persensitivity treatment, ${ }^{15}$ cleaning organic debris, ${ }^{16}$ and soft tissue surgery. ${ }^{17}$ According to literature, the Nd:YAG laser irradiation on dentin promotes its melting thereafter the sealing of the dentin tubules. Some bonding studies have shown that the Nd:YAG laser can also be applied before or after the adhesive systems. Few authors hinted that the use of Nd:YAG laser before self-etch adhesive systems improves the bond strength due to increased availability of calcium and phosphorus after laser application. ${ }^{18}$ Most authors suggested, however, that irradiation of dentin treated with either total etch or self-etch adhesive systems, prior to adhesive polymerization, could result in more stable bonding. ${ }^{13,19,20}$

Nevertheless, the interaction between remineralizing agents containing CPP-ACP and Nd:YAG laser on dentin bond strength is unknown. Hence, the purpose of this study was to investigate the effect of CPP-ACP treatment and Nd:YAG laser on the bond strength of softened dentin. The null hypotheses to be tested were: 1) The treatment with CPP-ACP pastes will not change softened dentin bond strength; 2 ) There will be no difference on bond strength values of softened dentin treated with CPP-ACP based pastes associated with Nd:YAG laser application.

\section{Methodology}

Thirty sound third molars were selected for this study. Teeth donors signed the informed consent forms and ethical approval was obtained from the Human Research Ethics Committee of São José dos Campos School of Dentistry - UNESP/Brazil (protocol no. 006/2011-PH/CEP). Teeth were cleansed of soft tissue and stored in $0.5 \%$ chloramine-t solution at $5^{\circ} \mathrm{C}$. All teeth were used within 3 months after extraction. Afterwards, teeth were sectioned transversely at the cemento-enamel junction in a high speed lathe (Nevoni, Sao Paulo, Brazil) with a water cooled diamond saw Dremel 454 (Dremel, Breda, The Netherlands) and the roots were discarded. Each crown was longitudinally sectioned, in order to produce buccal and lingual samples. The buccal/lingual enamel was ground to obtain a flat surface and expose approximately $3 \times 3 \mathrm{~mm}$ of dentin area using 600-grit silicon carbide paper (Fepa-P, Panambra, São Paulo, Brazil) under running water on the polishing machine DP-10 (Panambra, São Paulo, Brazil). Samples were measured with a thickness gauge (Wilcos, Petrópolis, Brazil) in order to ensure minimum of $2 \mathrm{~mm}$ length. Samples shorter than $2 \mathrm{~mm}$ were discarded. Each sample was then embedded in acrylic resin JET (Artigos Odontológicos Clássico, São Paulo, Brazil) and had the smear layer on dentin standardized using 600-grit wet silicon carbide paper (Fepa-P, Panambra, São Paulo, Brazil) for $60 \mathrm{~s}$.

The 60 samples were randomly divided into 3 groups according to the CPP-ACP treatment received: CG: Control group - Softened dentin with no CPP-ACP treatment; MP: Softened dentin treated with CPP-ACP paste - MI Paste (GC American Inc, Alsip, USA); MPP: Softened dentin treated with CPP-ACP + 900ppm NaF paste - MI Paste Plus (GC American Inc., Alsip, USA). Each group was further divided into 2 subgroups $(n=10)$ according to the laser application protocol: NL - No laser (application of adhesive system according to manufacturer's 
instruction followed by polymerization for $10 \mathrm{~s}$ ); L - Laser (application of adhesive system according to manufacturer's instruction followed by Nd:YAG laser irradiation prior to adhesive photopolymeraization). Table 1 lists the manufacturers, composition and batch number of materials used in this study.

\section{Dentin softening procedure}

Dentin softening consisted in the immersion of samples in $30 \mathrm{~mL}$ of Sprite Zero (ph 2.6, $30 \mathrm{~mL} /$ sample, $25^{\circ} \mathrm{C}$, Coca-Cola, Jacareí, Brazil) for $30 \mathrm{~min} .^{21,22,23,24}$ Afterwards, the samples were removed from the Sprite solution and rinsed with deionized water. Before and after softening procedure, the samples were stored in deionized water at room temperature.

\section{Application of CPP-ACP based pastes}

The groups that received application of CPP-ACP based pastes (MI Paste and MI Paste Plus) were treated as manufacturer's instructions: a single application of approximately $0.5 \mathrm{~mm}$ layer for 3 minutes. ${ }^{25}$ Then, the specimens were rinsed with running deionized water and kept slightly wet. Bonding was done immediately after paste application.

\section{Bonding procedure and restoration}

The self-etching adhesive system Clearfil SE Bond (Kuraray Medical Inc., Tokyo, Japan) was used for all groups according to the manufacturer's instructions: primer application for $20 \mathrm{~s}$, drying with mild air flow, bond application for $10 \mathrm{~s}$ followed by gently air flow drying. For the NL groups, adhesive was applied to dentin and light cured for $10 \mathrm{~s}$. For the $\mathrm{L}$ groups, adhesive was applied to dentin followed by the laser irradiation. The Nd:YAG laser Pulse Master 600 IQ (American Dental Technologies, Corpus Christi, USA) has a wavelength of $1064 \mu \mathrm{m}$ and a pulse duration of $140 \mu \mathrm{m}$. Parameters used were 1.4 $\mathrm{W}, 10 \mathrm{~Hz}, 140 \mathrm{~mJ} /$ pulse, with an optic fiber of 320 $\mu \mathrm{m}$, generating energy of $174 \mathrm{~J} / \mathrm{cm}^{2}$ per pulse. The laser was applied in a standard position; the optic fiber was perpendicular to the dental surface, located approximately $1 \mathrm{~mm}$ from dentin, scanning for $30 \mathrm{sin}$ noncontact mode. After laser application, the adhesive system was light cured for $10 \mathrm{~s}$. All samples were restored with Filtek Z350 XT (3M-ESPE, Saint Paul, USA). A resin block was incrementally built up with the support of a silicon mold in order to standardize to a height of $4 \mathrm{~mm}$. Light curing was performed by LED Curing Light Elipar Freelight 2 (3M ESPE, Saint Paul, USA), $1000 \mathrm{~mW} / \mathrm{cm}^{2}$ power density and light output verified by radiometer-led (Kondortech, São Carlos, Brazil) throughout the study.

\section{Bond strength testing}

After storage in distilled water at $37^{\circ} \mathrm{C}$ for $24 \mathrm{~h}$, the restored samples were sectioned perpendicularly to the adhesive interface using the slow speed cutting device 1010 Labcut (Extec Machines Technologies Inc., Enfield, USA) to produce $1 \mathrm{~mm}^{2}$ adhesive surface area

Table 1. Manufacturer, composition and batch number of the materials used.

\begin{tabular}{|c|c|c|c|}
\hline Type & Brand & Composition & Batch number \\
\hline Bonding System & $\begin{array}{l}\text { CLEARFIL SE BOND } \\
\text { Kuraray Medical Inc., } \\
\text { Tokyo, Japan. }\end{array}$ & $\begin{array}{l}\text { Primer: } \\
\text { MDP, HEMA, monomer, water, catalyst. } \\
\text { Bond: } \\
\text { MDP, HEMA, monomer, methacrylic acid, diester with microparticle, catalyst. }\end{array}$ & C13445 \\
\hline Resin Composite & $\begin{array}{c}\text { FILTEKMR Z350XT } \\
\text { 3M-ESPE, St Paul, USA. }\end{array}$ & $\begin{array}{l}\text { Ceramics treated with Silane, BIS-GMA, BIS-silane-treated silica, EMA, silica- } \\
\text { zirconia oxide treated with Silane, diuretano polyethylene glycol dimethacrylate } \\
\text { dimethacrylate, TEG-GMA, 2.6 BHT and pigments. }\end{array}$ & 1127200212 \\
\hline Topical Paste & $\begin{array}{l}\text { MI PASTETM } \\
\text { GC American Inc., } \\
\text { Alsip, USA. }\end{array}$ & $\begin{array}{l}\text { Water, glycerol, CPP-ACP, D-Sorbitol, CMC-Na, propylene glycol, silicon } \\
\text { dioxide, titanium dioxide, Xylitol, phosphoric acid, flavoring, zinc oxide, } \\
\text { sodium ethyl p-sacrina, hidroxibenzoatol, magnesium oxide, guar gum, propyl } \\
\text { p-hydroxybenzoate, butyl p-hydroxybenzoate. }\end{array}$ & $100125 \mathrm{M}$ \\
\hline Topical Paste & $\begin{array}{l}\text { MI PASTE PLUSTM } \\
\text { GC American Inc., } \\
\text { Alsip, USA. }\end{array}$ & $\begin{array}{l}\text { Water, glycerol, CPP-ACP, D-Sorbitol, CMC-Na, propylene glycol, silicon } \\
\text { dioxide, titanium dioxide, phosphoric acid, Xylitol, flavoring, sodium fluoride, } \\
\text { zinc oxide, sodium ethyl p-sacrina, hidroxibenzoatol, magnesium oxide, guar } \\
\text { gum, propyl p-hydroxybenzoate, butyl p-hydroxybenzoate }\end{array}$ & 1003251 \\
\hline
\end{tabular}


beam under water cooling. The beams were fixed to a microtensile bond strength metallic apparatus with the cyanoacrylate adhesive Loctite 454 (Loctite, São Paulo, Brazil), and stressed with a $10 \mathrm{~kg}$ load cell at a crosshead speed of $1.0 \mathrm{~mm} / \mathrm{min}$ using the universal testing machine DL-200MF (EMIC, São José dos Pinhais, Brazil). The cross-sectional area at the site of failure was measured with a digital caliper (Starret Indústria e Comércio Ltda., Itu, Brazil) and the formula $\mathrm{R}=\mathrm{F} / \mathrm{A}$ was used in order to calculate the strength $(\mathrm{R}=$ strength in $\mathrm{MPa} ; \mathrm{F}=$ load in $\mathrm{N} ; \mathrm{A}$ = interface area of the specimen in $\mathrm{mm}^{2}$ ). Fractured areas were stained with $7 \%$ hematoxylin solution and analyzed under the stereomicroscope Stemi 2000-C (ZEISS, Oberkochen, Germany) at 50X magnification. Failure modes were classified into adhesive at interface (A), cohesive failure in resin composite (CR), cohesive failure in dentin (CD) or mixed failure (M). ${ }^{13,26,27}$ Percentage of each type of failure was calculated and illustrated in Figure 1.

\section{Statistical Analysis}

For each subgroup, bond strength means and standard deviations were calculated and shown to present normal distribution (Kolmogoroff-Smirnoff test; $p=0.45$ ). Data was then evaluated by two-way ANOVA (independent factors: type of softened dentin treatment and laser application) followed by Holm-Sidak post-hoc method. Data were analyzed using the statiscal software Sigma Plot version 11.0 (Systat Software Inc., San Jose, USA) and level of significance was set at 0.05 .

\section{Results}

The mean bond strength values for all tested groups are presented in Table 2. ANOVA showed that there were no statistical differences in bond strength mean values among the softened dentin treatment groups (control and CPP-ACP-based pastes), leading to the acceptance of the first proposed null hypothesis. In other words, the treatment with CPP-ACP pastes did not significantly affect softened dentin bond strength $(p=0.070)$.

However, two-way ANOVA revealed a statistically significant interaction between both factors analyzed, softened dentin treatment and Nd:YAG laser application ( $\mathrm{p}<0.001)$. Holm-Sidak post-hoc method revealed significant reduction on bond strength values for the control group treated with laser, as compared with groups that were treated with CPP-ACP-based pastes and laser. This leads to the rejection of the second null hypothesis $(\mathrm{p}<0.001)$.

Microscopic analysis of fractured samples that did not receive laser treatment indicated predominant adhesive failures for control group and cohesive failure (CR) for CPP-ACP treated groups (Figure 1). The lased groups did not show a specific failure pattern.

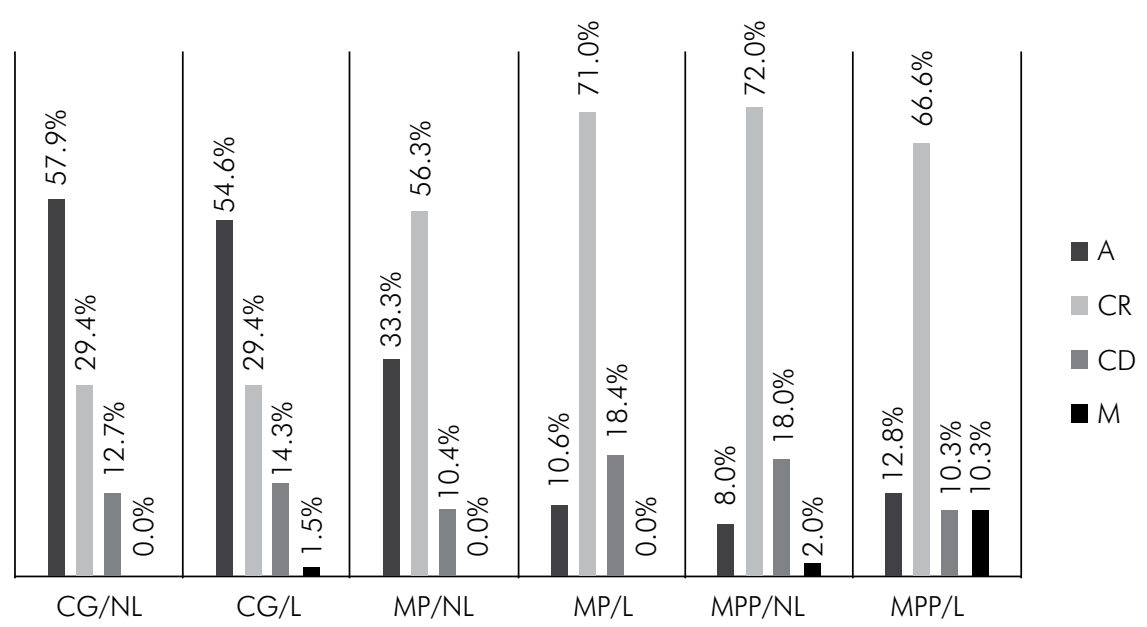

Figure 1. Percentage failure modes: $A$ : adhesive at interface; $C R$ : cohesive failure in resin composite; $C D$ : cohesive failure in dentin; M: mixed. 


\section{Discussion}

Remineralizing pastes have been recommended for preventive therapy of hypersensitivity and noncarious cervical lesions. However, it is believed that such products applied on dentin prior to the bonding procedure, might be able to compromise the bond strength due to dentin tubules obliteration, preventing bond penetration throughout the collagen fibrils. Adebayo et al. ${ }^{9}$ carried out a SEM (scanning electron microscopy) study in which it was possible to notice the presence of pastes' residue on dentin pre-treated with CPP-ACP. The authors concluded that certain adhesive systems applied to CPP-ACP treated surfaces could impair bond strength values. ${ }^{9,10}$ The results obtained in this study revealed that the bond strength of softened dentin was not affected by the application of any type of CPP-ACP based pastes. These findings may be related to the $10-\mathrm{MDP}$ (10 - methacryloxydecyl dihydrogen phosphate), functional monomer present in Clearfil SE Bond and its chemical interaction with the calcium phosphate deposited in dentinal tubules by CPP-ACP based pastes. Taking into account that self-etch adhesive systems demineralize partially the dentin, Yoshida et al. ${ }^{28}$ performed a comparative study to evaluate the performance of different functional monomers, and the results strongly suggested that 10-MDP has a high chemical bond to hydroxyapatite. Calcium and phosphate deposited by the pastes on dentin may have interacted ionically with 10-MDP, and therefore been beneficial to bonding procedures with Clearfil SE Bond. ${ }^{29}$

According to previous studies, Nd:YAG laser irradiation promotes dentin melting, denaturation of the organic components and recrystallization of dentin apatite with additional calcium phosphate

Table 2. Mean Microtensile Bond Strength Values (MPa) and Standard Deviations (SD).

\begin{tabular}{lccc}
\hline Group & Laser treatment & $\mathrm{MPa}$ & $\mathrm{SD}$ \\
\hline $\mathrm{CG}$ & $\mathrm{NL}$ & $35.184^{\mathrm{a}}$ & 1.50 \\
& $\mathrm{~L}$ & $29.625^{\mathrm{b}}$ & 4.44 \\
$\mathrm{MP}$ & $\mathrm{NL}$ & $33.473^{\mathrm{a}}$ & 2.44 \\
& $\mathrm{~L}$ & $36.445^{\mathrm{a}}$ & 2.50 \\
$\mathrm{MPP}$ & $\mathrm{NL}$ & $35.207^{\mathrm{a}}$ & 1.35 \\
& $\mathrm{~L}$ & $33.985^{\circ}$ & 5.59
\end{tabular}

phases. Dentin is consisted of around 70\% mineral which is necessary to melting and recrystallization after laser irradiation. ${ }^{30}$ Some studies suggest that the use of Nd:YAG laser before self-etch adhesive systems improves the bond strength due to increased availability of calcium and phosphorus after laser application. ${ }^{18}$ However, some authors reported that when the Nd:YAG laser is applied before adhesive systems, decreased bond strength values may occur due to tubules obliteration as well as the difficulty of acid etching the melted dentin. On the other hand, increased bond strength values have been also reported when the samples are irradiated after adhesive system application and before polymerization. This is due to the incorporation of the adhesive monomers into dentin, during the melting and recrystallization processes, thereby resulting in a tougher substrate. ${ }^{13,19,20}$

The current study evaluated the influence of Nd:YAG laser irradiation after adhesive application on the bond strength of softened dentin. The results showed a significant decrease on bond strength values for the group that did not receive CPP-ACP treatment. This result may be related to the reduced mineral content in the softened dentin, necessary for melting and recrystallization. The groups treated with CPP-ACP based pastes followed by irradiation did not show significant differences as compared with the non-irradiated groups. This most likely happened because the calcium and phosphate ions released by the pastes may have replaced missing contents of mineral on softened dentin.

Prevalent cohesive failure in resin composite (CR) was observed within the groups treated with CPP-ACP based pastes. Both groups, MP and MPP presented over $50 \%$ of $C R$, independently of laser irradiation. Conversely, the control group presented the adhesive failure (57.9\% NL group and $54.6 \%$ L group) as the most predominant mode of failure. This finding suggests that the treatment with both pastes have somehow influenced the failure mode, presumably due to the chemical bonding with calcium in dentin. ${ }^{28}$ Comparing the irradiated and non-irradiated samples within the same group, the distribution of failure modes has shown a similar pattern. Accordingly, the Nd:YAG laser was not able to influence the mode of failure. ${ }^{13}$ 


\section{Conclusion}

Under the limitations of this in vitro study, it can be concluded that the CPP-ACP based pastes did not affect the microtensile bond strength of softened dentin. The Nd:YAG laser irradiation after application of adhesive system did affect the bond strength values of softened dentin samples untreated with CPP-ACP based pastes. Hence, since the results showed no negative interference of the pastes on microtensile bond strength with Clearfil SE Bond adhesive system, the tested CPP-ACP based pastes may be indicated for the treatment of hypersensitivity on tooth with exposed dentin. Nevertheless, if the exposed surface requires a future restoration, the

\section{References}

1. Wang X, Lussi A. Assessment and management of dental erosion. Dent Clin North Am. 2010 Jul;54(3):565-78.

2. Bartlett D. Intrinsic causes of erosion. Monogr Oral Sci. 2006 Jun;20:119-39.

3. Lussi A, Jaeggi T. Chemical factors. Monogr Oral Sci. 2006 Jun;20:77-87.

4. Reynolds EC. Remineralization of enamel subsurface lesions by casein phosphopeptide-stabilized calcium phosphate solutions. J Dent Res. 1997 Sep;76(9):1587-95.

5. Rahiotis C, Vougiouklakis G. Effect of a CPP-ACP agent on the demineralization and remineralization of dentine in vitro. J Dent. 2007 Aug;35(8):695-8.

6. Poggio C, Lombardini M, Vigorelli P, Ceci M. Analysis of dentin/enamel remineralization by a CPP-ACP paste: AFM and SEM study. Scanning. 2013 Nov-Dec;35(6):366-74.

7. Hamba H, Nikaido T, Inoue G, Sadr A, Tagami J. Effects of CPP-ACP with sodium fluoride on inhibition of bovine enamel demineralization: a quantitative assessment using micro-computed tomography. J Dent. 2011 Jun;39(6):405-13.

8. Srinivasan N, Kavitha M, Loganathan SC. Comparison of the remineralization potential of CPP-ACP and CPP-ACP with 900 ppm fluoride on eroded human enamel: An in situ study. Arch Oral Biol. 2010 Jul;55(7):541-4.

9. Adebayo OA, Burrow MF, Tyas MJ. Dentine bonding after CPP-ACP paste treatment with and without conditioning. J Dent. 2008 Dec;36(12):1013-24.

10. Adebayo OA, Burrow MF, Tyas MJ. Resin-dentine interfacial morphology following CPP-ACP treatment. J Dent. 2010 Feb;38(2):96-105.

11. Borges BC, Souza-Junior EJ, Costa GF, Pinheiro IV, Sinhoreti MA, Braz R, et al. Effect of dentin pre-treatment with a casein phosphopeptide-amorphous calcium phosphate (CPP-ACP) adhesive system should be chosen carefully. However, a proper diagnosis is necessary to indicate the use of Nd:YAG laser with adhesive restorations, since the Nd:YAG laser cannot apparently be applied on softened dentin. Future studies should evaluate the adhesive interface morphology of softened dentin treated with CPP-ACP based pastes associated with Nd:YAG laser.

\section{Acknowledgments}

The authors express their appreciation to FAPESP (Fundação de Amparo à Pesquisa do Estado de São Paulo) 2011/10827-4 and CAPES (Coordenação de Aperfeiçoamento de Pessoal de Nível Superior).

paste on dentin bond strength in tridimensional cavities. Acta Odontol Scand. 2013 Jan;71(1):271-7.

12. Acar O, Tuncer D, Yuzugullu B, Celik C. The effect of dentin desensitizers and Nd:YAG laser pre-treatment on microtensile bond strength of self-adhesive resin cement to dentin. J Adv Prosthodont. 2014 Apr;6(2):88-95.

13. Marimoto AK, Cunha LA, Yui KC, Huhtala MF, Barcellos DC, Prakki A, et al. Influence of Nd:YAG laser on the bond strength of self-etching and conventional adhesive systems to dental hard tissues. Oper Dent. 2013 Jul-Aug;38(4):447-55.

14. Rios D, Magalhaes AC, Machado MA, Silva SM, Lizarelli RF, Bagnato VS, et al. In vitro evaluation of enamel erosion after Nd:YAG laser irradiation and fluoride application. Photomed Laser Surg. 2009 Oct;27(5):743-7.

15. Lopes AO, Aranha AC. Comparative evaluation of the effects of Nd:YAG laser and a desensitizer agent on the treatment of dentin hypersensitivity: a clinical study. Photomed Laser Surg. 2013 Mar;31(3):132-8.

16. Hasheminia SM, Birang R, Feizianfard M, Nasouri M. A comparative study of the removal of smear layer by two endodontic irrigants and Nd:YAG Laser: a scanning electron microscopic study. ISRN Dent. 2012;2012:620951.

17. Romanos GE. Clinical applications of the Nd:YAG laser in oral soft tissue surgery and periodontology. J Clin Laser Med Surg. 1994 Apr;12(2):103-8.

18. Rolla JN, Mota EG, Oshima HM, Burnett Junior LH, Spohr AM. Nd:YAG laser influence on microtensile bond strength of different adhesive systems for human dentin. Photomed Laser Surg. 2006 Dec;24(6):730-4.

19. Goncalves SE, Araujo MA, Damiao AJ. Dentin bond strength: influence of laser irradiation, acid etching, and hypermineralization. J Clin Laser Med Surg. 1999 Apr;17(2):77-85. 
20. Matos AB, Oliveira DC, Navarro RS, Eduardo CP, Matson E. Nd:YAG laser influence on tensile bond strength of selfetching adhesive systems. J Clin Laser Med Surg. 2000 Oct;18(5):253-7.

21. Wongkhantee S, Patanapiradej V, Maneenut C, Tantbirojn D. Effect of acidic food and drinks on surface hardness of enamel, dentine, and tooth-coloured filling materials. J Dent. 2006 Mar;34(3):214-20.

22. Barbosa CS, Kato MT, Buzalaf MA. Effect of supplementation of soft drinks with green tea extract on their erosive potential against dentine. Aust Dent J. 2011 Sep;56(3):317-21.

23. Hara AT, Zero DT. Analysis of the erosive potential of calcium-containing acidic beverages. Eur J Oral Sci. 2008 Feb;116(1):60-5.

24. Lussi A, Kohler N, Zero D, Schaffner M, Megert B. A comparison of the erosive potential of different beverages in primary and permanent teeth using an in vitro model. Eur J Oral Sci. 2000 Apr;108(2):110-4.

25. Panich M, Poolthong S. The effect of casein phosphopeptide-amorphous calcium phosphate and a cola soft drink on in vitro enamel hardness. J Am Dent Assoc. 2009 Apr;140(4):455-60.

26. Sengun A, Unlu N, Ozer F, OztUrk B. Bond strength of five current adhesives to caries-affected dentin. J Oral Rehabil. 2002 Aug;29(8):777-81.

27. Corazza PH, Cavalcanti SC, Queiroz JR, Bottino MA, Valandro LF. Effect of post-silanization heat treatments of silanized feldspathic ceramic on adhesion to resin cement. J Adhes Dent. 2013 Oct;15(5):473-9.

28. Yoshida Y, Nagakane K, Fukuda R, Nakayama Y, Okazaki $M$, Shintani $H$, et al. Comparative study on adhesive performance of functional monomers. J Dent Res. 2004 Jun;83(6):454-8.

29. Pei D, Liu S, Huang C, Du X, Yang H, Wang Y, et al. Effect of pretreatment with calcium-containing desensitizer on the dentine bonding of mild self-etch adhesives. Eur J Oral Sci. 2013 Jun;121(3 Pt 1):204-10.

30. Moriyama EH, Zangaro RA, Villaverde AB, Lobo PD, Munin E, Watanabe IS, et al. Dentin evaluation after Nd:YAG laser irradiation using short and long pulses. J Clin Laser Med Surg. 2004 Feb;22(1):43-50. 